\title{
Using the Lonsdorf model for estimating habitat loss and fragmentation effects on pollination service
}

\author{
Ehsan Rahimi ${ }^{*} \mathbb{D}$, Shahindokht Barghjelveh ${ }^{1}$ and Pinliang Dong ${ }^{2}$
}

\begin{abstract}
One of the most important issues related to landscape ecology and ecosystem services is finding the pattern of habitat patches that offers the highest pollination in agricultural landscapes. In this regard, two processes of habitat loss and fragmentation strongly affect the relationship between pollination and the pattern of habitat patches. In the present study, we aimed to examine the effects of habitat loss and fragmentation on pollination separately. For this purpose, first, we generated different simulated agricultural landscapes, including two habitats of forest and agriculture. Then, according to the Lonsdorf model, we estimated the potential of the simulated landscapes in providing pollination in different scenarios. Finally, using statistical models, we estimated the effects of habitat loss and fragmentation on pollination at the landscape and farm levels. Our results showed that the effects of habitat loss and fragmentation on pollination were completely different at the landscape and farm levels. At the landscape level, fragmentation negatively affected pollination, but at the farm level, the maximum pollination rate was observed in the landscapes with a high degree of fragmentation. Regarding the habitat loss effects, our results showed that pollination decreased linearly at the landscape level as habitat amount decreased, but at the farm level, it decreased exponentially. The present study considered the level of analysis (i.e., landscape and farm levels) as a critical factor affecting pollination changes caused by fragmentation. We showed that using the Lonsdorf model could lead to confusing results for the landscape ecologists and alert farmers who want to reduce the adverse effects of fragmentation on their products by creating new forest patches. Therefore, agriculturalists and landscape ecologists should consider that the pollination rate at the landscape and farm levels is completely different according to the model and provide contradictory results about the process of habitat loss effects on pollination.
\end{abstract}

Keywords: Landscape ecology, Pollination service, Habitat loss, Fragmentation, Landscape metrics, Lonsdorf model

\section{Introduction}

Pollinators have significant economic value, and at least $35 \%$ of the world's food products are directly dependent on these organisms (Klein et al. 2007). Although farmers typically use honeybees to pollinate their crops, the recent decline in their activity and population (Potts et al. 2010) has focused on wild bees and their function in nature. In the absence of honeybees, several studies have

\footnotetext{
* Correspondence: ehsanrahimi666@gmail.com

${ }^{1}$ Environmental Research Institute, Shahid Beheshti University, Tehran, Iran

Full list of author information is available at the end of the article
}

reported that wild bees could increase agricultural yields, especially in orchards (Garibaldi et al. 2013). For example, for some crops such as blueberries, wild bees are more efficient than honeybees (Kevan et al. 1990). In recent years, concern has aroused related to decreasing pollinator population worldwide (Viana et al. 2012; Potts et al. 2016). Today, agriculture is more dependent on pollinators, and the shortage of pollinators increases the demand for arable land, which is more critical in developing countries (Aizen et al. 2009). This has given rise

\section{Springer Open}

(- The Author(s). 2021 Open Access This article is licensed under a Creative Commons Attribution 4.0 International License, which permits use, sharing, adaptation, distribution and reproduction in any medium or format, as long as you give appropriate credit to the original author(s) and the source, provide a link to the Creative Commons licence, and indicate if changes were made. The images or other third party material in this article are included in the article's Creative Commons licence, unless indicated otherwise in a credit line to the material. If material is not included in the article's Creative Commons licence and your intended use is not permitted by statutory regulation or exceeds the permitted use, you will need to obtain permission directly from the copyright holder. To view a copy of this licence, visit http://creativecommons.org/licenses/by/4.0/. 
to rapidly growing studies identifying pollinator threats in the agricultural landscapes.

Wild bees often rely on non-agricultural habitats (such as forests) for nesting; they move from these habitats to farms to carry out the pollination process (Ricketts et al. 2008). There is strong evidence that landscape structure changes (such as the size, arrangement, and shape of patches) have significant effects on wild bees (Syrbe and Walz 2012). Therefore, in terms of pollination in agricultural landscapes, it is of high importance to understand how wild bees are affected by landscape configuration (Olsson et al. 2015). It has been demonstrated that the abundance of wild bees and their diversity in habitats such as farms depend not only on the quality of the farms but also on the distance between the nesting habitats and the patches of their foraging habitat (Ekroos et al. 2013; Gathmann et al. 1994; Ricketts et al. 2008; Steffan-Dewenter and Schiele 2008). In addition to a sufficient amount of nesting habitat, a landscape should provide sufficient floral resources for pollinators (Kline and Joshi 2020).

Habitat loss and fragmentation processes are known as primary threats to pollinators (Winfree et al. 2009). Habitat loss and fragmentation often occur simultaneously but have different ecological effects. Habitat loss occurs when the habitat amount is decreasing, and if this trend continues, the habitat will disappear. In contrast, fragmentation is breaking a single large habitat patch into multiple smaller ones. It is well established that habitat loss and fragmentation have devastating effects on biodiversity and ecosystem services (Haddad et al. 2015). These processes isolate natural habitat fragments, such as forests, surrounded by agricultural fields (Fahrig et al. 2011). The isolation of the natural patches exerts influence over the ecosystem service provision since it affects the movement ability of organisms (Mitchell et al. 2014).

Habitat loss and fragmentation make it challenging to find nesting sites and floral resources because bees need their nesting and floral habitats to be adjacent (Kline and Joshi 2020). Habitat loss affects the abundance and diversity of pollinators mainly because of decreasing floral resources (Winfree et al. 2011). This would be more critical for the wild bees which nest in tree cover (Kline and Joshi 2020). Habitat loss results in decreasing flower density in an area consequently reduce visiting rate (Hegland and Boeke 2006), which can change foraging behavior (Dauber et al. 2010). Habitat loss also negatively affects the wild bee's accessibility to food resources, and they have to move more distance and take more time to find food, leading to reduced protein content in the larvae (Kline and Joshi 2020).

The results of studies examining the effects of habitat loss and fragmentation show that the effects of fragmentation are more notable at low habitat amounts (Maurer et al. 2020; Rybicki and Hanski 2013). This nonlinear fragmentation hypothesis states that landscape configuration is significant only below a critical proportion of habitat, around 10-30\% (Fahrig 1998) because patches are small and isolated enough to prevent organisms from moving in the landscape (Gardner et al. 1991). The responses of pollination service are expected to be nonlinear concerning fragmentation effects (Tscharntke et al. 2008), meaning that the adverse effects of fragmentation on pollination occur when the amount of the habitat of interest is low, i.e., less than $10 \%$ of the total landscape. Mitchell et al. (2015a) examined the effects of habitat loss on distance-dependent services such as pollination. They predicted that the highest levels of distance-dependent ecosystem services occurred in landscapes with moderate habitat amounts and fragmentation. At moderate habitat amounts, Mitchell et al. (2015b) also found that when the effects of fragmentation on ecosystem service supply were opposite flow, ecosystem services reached their maximum.

Most studies investigate fragmentation simultaneously with habitat loss (Fletcher Jr et al. 2018), while habitat fragmentation independent of habitat loss has a different meaning and is known as "fragmentation per se" (Fahrig 2017). Fragmentation per se implies that the habitat amount in a landscape is constant, and only the patches' configuration changes. Therefore, it is possible to manage the ecosystem service provision by controlling the natural patches' configuration (Fahrig et al. 2011). The effects of fragmentation per se on biodiversity are much weaker than habitat loss, and they are often useful. For example, Fahrig (2017) reviewed 381 studies related to habitat fragmentation per se effects on biodiversity. They found that 290 (76\%) of them reported positive effects of fragmentation per se. Maurer et al. (2020) also emphasized the importance of studying the effects of fragmentation per se on pollinators to guide the spatial optimization of landscapes to increase pollination. However, it is difficult and time-consuming to predict the effects of habitat loss and fragmentation per se on pollination based on field experiments and surveys. Therefore simulationbased predictions are recommended (Häussler et al. 2017). In landscape ecology, we can examine the effects of habitat loss and fragmentation on pollination at four levels according to a logical hierarchical organization of spatial heterogeneity in a landscape (McGarigal et al. 2002): (1) cell, (2) patch, (3) class, and (4) landscape. At the class level, the within-patch heterogeneity is ignored, and all patches related to a certain cover are assigned a distinct value to represent the composition of the patches. At the landscape level, we focus on the spatial aspects and distribution of all patches related to all covers in the landscape. 
Lonsdorf and colleagues proposed a model in 2009 that has been widely used in predicting pollinator abundance in a landscape (Lonsdorf et al. 2009). This model assumes that the wild bees return to the nest after collecting pollen and nectar. So, the visiting rate in a patch with floral resources depends on the distance between the nesting habitat and the patch (Lonsdorf et al. 2009). Initially, it develops an indicator to estimate the relative abundance of species in nesting habitats based on the pollinator species' habitat needs, food resource availability, and foraging ability of the pollinating bees. In the next step, it predicts the abundance of each pollinating bee in the agricultural fields. According to the model, natural habitats such as forests are assumed mostly to provide nesting habitats for pollinating bees, while the surrounding areas are assumed to be used for foraging. Pollination in natural forest fragments is an ecosystem function and is different from crop pollination that is an ecosystem service. The Lonsdorf model considers both ecosystem function and service of land covers and displays them together on a map. This model logically predicts pollination in a landscape (Kennedy et al. 2013) and is the first explicit spatial model in this field (Lonsdorf et al. 2009). The Integrated Valuation of Ecosystem Services and Tradeoffs (InVEST) software, as a widely used tool in ecosystem service mapping, contained the Lonsdorf model to estimate pollination (Sharp et al. 2014). Notably, the Lonsdorf model assumes that pollinators' abundance is equal to pollination. In other words, the more pollinators, the more pollination. Although pollinators' existence in an area does not always mean pollination, it can be regarded as a pollination proxy. Therefore, the output of the Lonsdorf model is considered a pollination map (Lonsdorf et al. 2009). Similarly, in this study, we assumed the output of the Lonsdorf model as a pollination map. Although the Lonsdorf model is utilized in many studies to estimate pollination, none of them has modeled the effect of habitat loss and fragmentation per se on pollination using the model. Considering the background previously discussed, this research was conducted using the Lonsdorf model to answer the critical questions as follows: (1) What are the effects of habitat loss and fragmentation per se on pollination? (2) Which pattern of forest patches offers the highest pollination level in an agricultural landscape? (3) Which of the landscape metrics can be considered as a proxy for pollination?

\section{Materials and methods}

\section{Generating simulated landscapes}

Compared to real-world landscapes, simulated models have fewer limitations and enable us to examine certain aspects of a landscape. In the present study, we generated simulated agricultural landscapes, including two classes of forest and agriculture. Using the NLMR package (Sciaini et al. 2018) in R software, maps with dimensions of 50 by 50 cells with different proportions of forest habitat and degrees of fragmentation per se were produced (Fig. 1). The proportions of forest habitat were variable from 5 to $50 \%(0.05,0.1,0.2,0.3,0.4$, and 0.5$)$ of the entire landscape. At each of these proportions, the degree of fragmentation per se changed from highest $(0.01)$ to lowest $(0.5)$ using parameter $p$ (the proportion of elements randomly selected to form clusters) in the NLMR package. We considered each cell area being 100 $\mathrm{m}^{2}$, meaning that each landscape covers an area of 2500 ha. To examine the effects of habitat loss on pollination, we used the GradientLand software (Cambui et al. 2015) to produce a set of landscapes that at each stage a certain amount of habitat was reduced so that in the last stage the entire habitat was destroyed. The GradientLand software creates random and fractal simulated landscapes. For fractal landscapes, it uses the parameter $H$ termed the Hurst exponent (Feder 2013) to determine the forest fragmentation rate. In the present study, both random and fractal series were used (Fig. 2).

\section{Estimating pollination in simulated agricultural landscapes}

The assumptions of the Lonsdorf model are as follows:

(1) The Lonsdorf model assumes that each habitat in a landscape such as agriculture, forest, pasture,

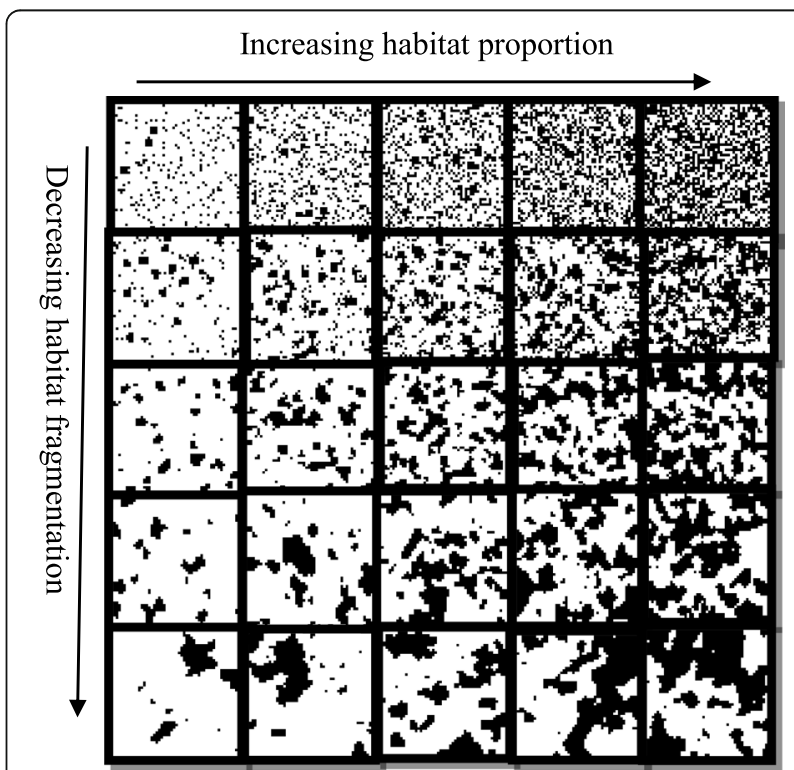

Fig. 1 Examples of simulated agricultural landscapes in different forest proportions (black patches) and degrees of fragmentation. In this figure, the habitat amount is constant in each column, and only the degree of fragmentation changes. In each row, the habitat amount increases from landscapes on left to the right ones 


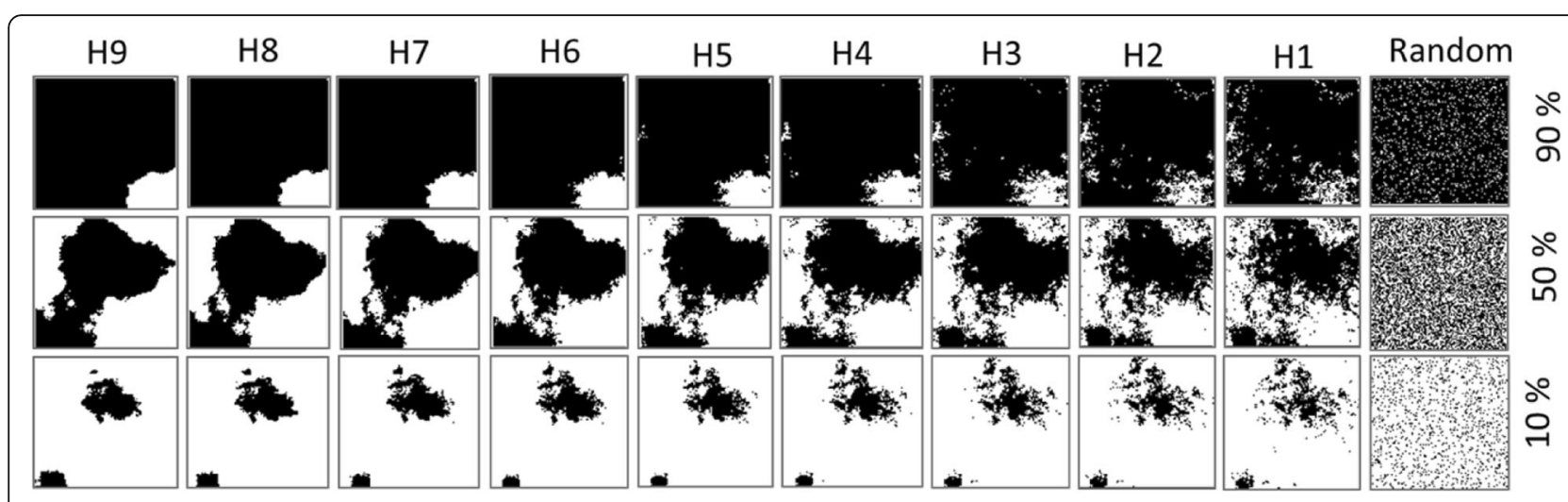

Fig. 2 Examples of simulated landscapes of the GradientLand software with random pattern and nine levels of Hurst exponents for fractal. In this figure, the random pattern has the most fragmented pattern, and for the fractal pattern, the degree of fragmentation decreases from $\mathrm{H} 1$ to $\mathrm{H} 9$

and the city could have the potential of providing both nesting and foraging habitats. This model considers the potential of each patch in providing mentioned habitats between 0 and 1 . For example, for forest habitat in a landscape, a high potential for nesting habitat can be considered one and at the same time, if it does not provide any food, meaning that no floral resources can be found in the forest, the zero is considered for its potential.

(2) The model first estimates the fitness or suitability of the patches for nesting according to the potential of the patches themselves in providing nesting habitat and the floral resources around them (Eq. 1). In evaluating floral resources around the nests, near pixels weigh more than distant ones according to the ability of the bees to move $(\alpha)$. The result is a map showing the fitness of nests between 0 and 1 .

(3) This model assumes that all landscape cells are involved in determining the patch potential in providing nesting habitats, even those that are beyond the foraging range of bees $(\alpha)$.

(4) In the next step, the model predicts the relative abundance of visiting bees in agricultural fields according to the desirability of the nests (Eq. 2). It assumes that the abundance of bees decreases exponentially with increasing distance from the nesting patches.

(5) In cases that nesting patches have a higher value than surrounding floral resources, the central cells of the patches always receive the highest scores, and the marginal cells receive lower scores. Therefore, in the output maps resulting from this model, it can be seen that the central cells of the patches are most likely to be pollinators.

$$
G_{i}=N_{i} \frac{\sum_{j=1}^{M} F_{j} e^{-D_{i j / \alpha}}}{\sum_{j=1}^{M} e^{-D_{i j / \alpha}}}
$$

In this equation, if the habitat is suitable for nesting the desired species, $N_{i}$ is equal to 1 and otherwise equal to $0 . D_{i j}$ is the Euclidean distance between nesting cells $(i)$ and floral resource cells $(j)$. The numerator is the total weight of the distance between all cells of floral resources adjacent to nesting patches. The quality of these cells $\left(F_{j}\right)$ is between 0 and 1 . In many agricultural landscapes, the abundance and variety of bees are reduced at distances of 50 to $500 \mathrm{~m}$ from forest patches (Bailey et al. 2014). In the Lonsdorf model, $\alpha$ determines the average distance that a bee can travel from forest patches to agricultural lands. We considered $\alpha$ being 10 pixels. The output map of Eq. 1 shows the fitness of the nesting patches for wild bees between 0 and 1 .

$$
P_{j}=\frac{\sum_{j=1}^{M} G_{i} e^{-D_{i j / \alpha}}}{\sum_{j=1}^{M} e^{-D_{i j / \alpha}}}
$$

To determine the bees' abundance on farms, similar to the framework of Eq. 1, cells from farms that are closer to the nesting habitats receive more probability of wild bee abundance. Thus, the abundance index of $P$ in $j$ cells is calculated according to Eq. 2, in which $G_{i}$ shows the fitness of nesting patches that was obtained in the first step. In the present study, the relationship between 
landscape patterns and pollination was estimated at two levels: (1) The relationship between landscape structure and the average pollination rate in each landscape cell, including floral resources and nesting habitats (at landscape level). (2) This relationship was examined only based on the average pollination rate on the farm habitat (at class level). These steps were performed separately for the two processes of habitat loss and fragmentation per se.

\section{Landscape metrics}

Landscape metrics measure two fundamental aspects of landscape structure: composition and configuration. Landscape composition refers to the variety and abundance of patch types regardless of their spatial aspects of distribution. Landscape configuration refers to the spatial aspects or distribution and position of landscape components (Leitão et al. 2012). In the present study, nine commonly used metrics were calculated for all simulated landscapes using the Fragstats software (McGarigal et al. 2002) at the landscape and class levels (Table 1). Stepwise multiple regression was performed in the Minitab software to determine the direction and magnitude of the interaction between the landscape metrics and pollination. In this research, we used the stepwise method, which starts at the forward selection, but the possibility of deleting a predictor, as backward elimination, is considered at each stage (Chong and Jun 2005). The probability value for entering variables into the stepwise models was set at 0.05 , and the probability to remove was set at 0.1 . This procedure automatically selects variables that are significantly important in the model using different procedures (Ryan et al. 2012). The last model presented in Minitab will be the best found using stepwise regression. The advantage of stepwise regression is that this method selects the best subset of independent variables that are not correlated with each other, and therefore considers multicollinearity between predictors. In the present study, pollination was considered as the dependent variable, and all landscape metrics were included as predictors in the regression models.

\section{Results}

The effect of habitat fragmentation per se on pollination at the landscape and farm levels

Figure 3 illustrates the pollination changes against the fragmentation of nesting habitat in different habitat proportions at the landscape level. In this figure, the vertical axis shows the average pollination rate at the landscape level, and the horizontal axis demonstrates the degree of fragmentation per se, which decreases from 0.1 to 0.5 . Concerning Fig. 3, it can be seen that the maximum level of pollination was obtained at the minimum level of habitat fragmentation per se. In other words, fragmented patterns of forest patches reduced pollination at the landscape level. It is noteworthy that the difference

Table 1 Descriptions of the selected landscape metrics. In this table, several metrics related to area and edge, shape, and aggregation categories have been presented that all of them measure landscape configuration aspects

\begin{tabular}{|c|c|c|c|}
\hline Category & Metric & Equation & Range \\
\hline \multirow[t]{2}{*}{ Area and edge } & Area-MN & $\frac{\sum_{j=1}^{n} x_{i j}}{n_{i}}$ & Area-MN > 0 \\
\hline & $\mathrm{ED}$ & $\frac{\sum e_{i k}}{A}(10000)$ & $0 \leq \mathrm{ED}$, no limit \\
\hline Shape & PAFRAC & $\overline{\left.\sum_{j=1}^{n} \ln p_{i j}-\ln a_{i j}\right]-\left[\left(\sum_{j=1}^{n} \ln p_{i j}\right)\left(\left(\sum_{j=1}^{n} \ln a_{i j}\right)\right)\right]}$ & $1 \leqq$ PAFRAC $\leqq 2$ \\
\hline \multirow[t]{6}{*}{ Aggregation } & LSI & $\frac{0.25 \sum e_{i k}}{\sqrt{A}}$ & $1 \leq \mathrm{LSI}$ \\
\hline & DIVISION & {$\left[1-\sum\left(\frac{a_{i j}}{A}\right)^{2}\right]$} & $0 \leq \mathrm{DIVISION} \geq 1$ \\
\hline & SPLIT & $\frac{A^{2}}{\sum_{j=1}^{n} a_{i j}^{2}}$ & $1 \leqq S P L I T \leqq$ number of cells in the landscape area squared \\
\hline & $\mathrm{Al}$ & $\left(\frac{g_{i i}}{\max \rightarrow g_{i j}}\right)(100)$ & $0 \leq \mathrm{Al} \geq 100$ \\
\hline & NP & $n_{i}$ & $N P \geq 1$ \\
\hline & ENN & $h_{i j}$ & $E N N>0$ \\
\hline
\end{tabular}

$a_{i j}$ area $\left(\mathrm{m}^{2}\right)$ of patch, $A$ total landscape area $\left(\mathrm{m}^{2}\right), n_{i}$ number of class $i$ patches in the landscape, $e_{i j}$ total length $(\mathrm{m})$ of edges of patch $i j$, including landscape boundary, $c$ area $\left(\mathrm{m}^{2}\right)$ within patch $i j$ separated from its boundary by a user-specified buffer width $(\mathrm{m}), g_{i i}$ the number of adjacencies (contiguity) between pixels of patch class $i$, max $g_{i i}$ maximum possible number of adjacencies among pixels of patches of class $i, h_{i j}$ distance $(\mathrm{m})$ from patch $i j$ to the nearest neighboring patch of the same type (class), based on patch edge-to-edge distance, computed from cell center to cell center (McGarigal et al. 2002) 


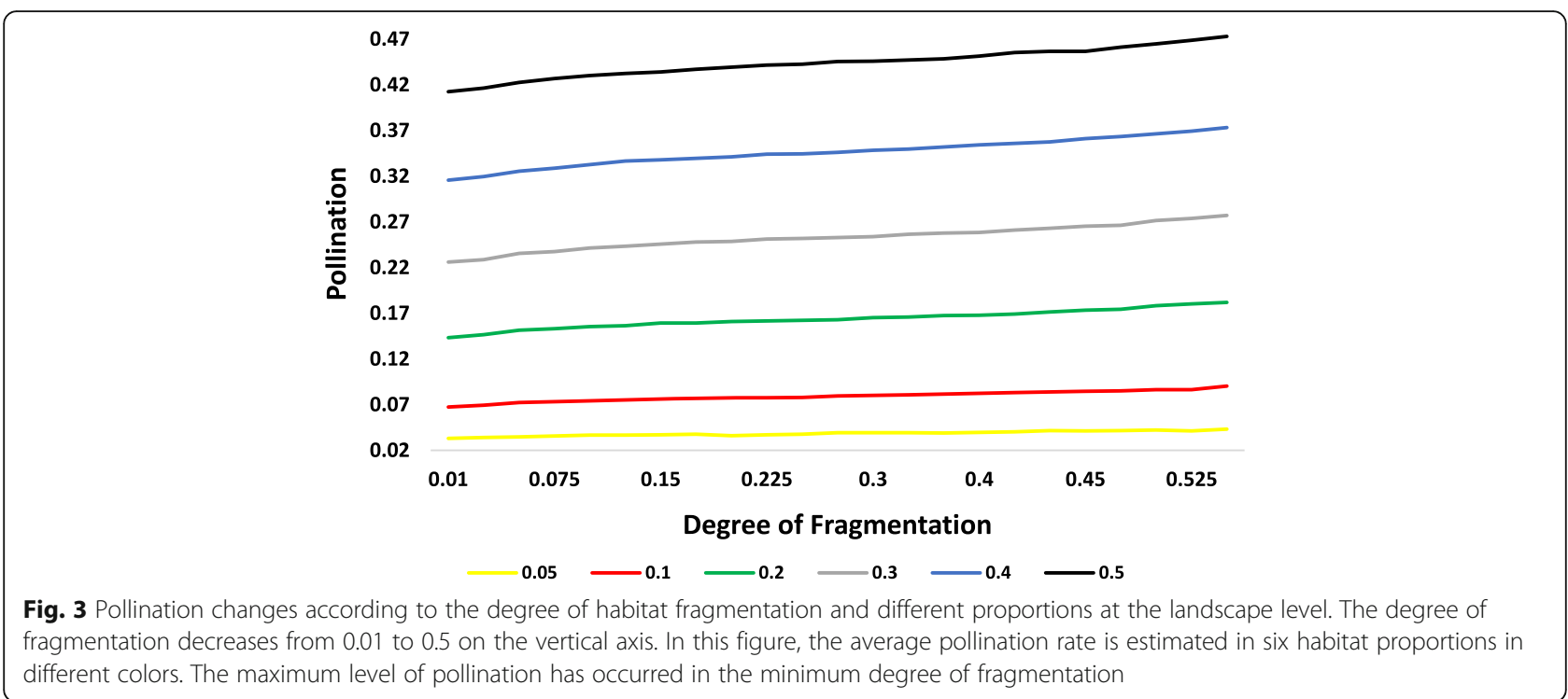

between the maximum and minimum levels of pollination, especially in proportions less than 0.1 , was not remarkable. Figure 4 shows the pollination changes at the farm level concerning fragmentation per se and different forest proportions. Inconsistent with landscape level, pollination declined as fragmentation increased at the farm level. Therefore, the maximum level of pollination was observed at the maximum levels of fragmentation per se. This result was more considerable in high habitat amounts, i.e., 0.4 and 0.5 of the entire landscape. Similar to the landscape level, the relationship between fragmentation per se and pollination was linear, and there was no notable difference in the level of pollination in fragmented and aggregated patterns at the farm level. The most notable result was that according to the Lonsdorf model, the effects of fragmentation per se on pollination at the landscape and class levels were completely different and opposite to each other. Another important result was the difference between maximum and minimum levels of pollination that remained relatively unchanged concerning fragmentation per se trend in low habitat amounts (less than 0.1).

Table 2 demonstrates the statistical relationship between landscape metrics and pollination at landscape and farm levels. This table provides more information about the pollination changes caused by fragmentation per se. In this table, $P$ is the abbreviation of pollination that was considered as the dependent variable in the regressions models. In the habitat fragmentation per se trend, some landscape metrics like the number of patches (NP), edge density (ED), perimeter-area fractal dimension (PAFRAC), and division index (DIVISION)

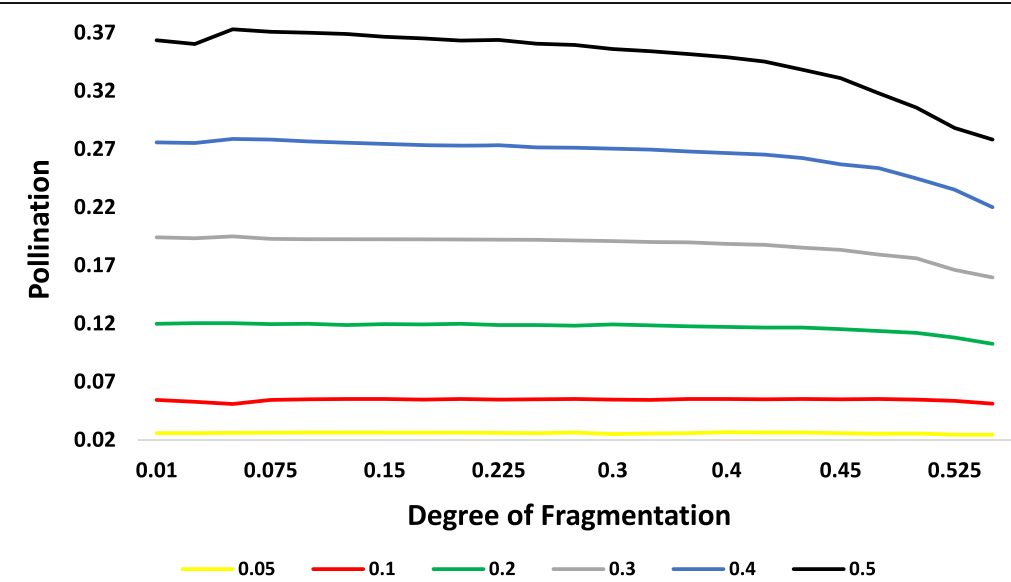

Fig. 4 Pollination changes according to the level of habitat fragmentation and different proportions at the farm level. The degree of fragmentation decreases from 0.01 to 0.5 on the vertical axis. In this figure, the average pollination rate is estimated in six habitat proportions in different colors. The maximum level of pollination has occurred in the maximum degree of fragmentation 
Table 2 The statistical relationship between landscape metrics and pollination at landscape and farm levels. $P$ is the abbreviation of pollination that is the dependent variable in the regression models

\begin{tabular}{|c|c|c|c|c|}
\hline Scale & Proportion & Equation & R-Sq (\%) & R-Sq (adj) (\%) \\
\hline \multirow[t]{6}{*}{ Landscape level } & 0.05 & $P=1.597-1.571 \mathrm{DIVISION}$ & 61.65 & 59.83 \\
\hline & 0.1 & $P=0.074138-0.000059 \mathrm{NP}+0.002282$ ENN_MN & 98.82 & 98.70 \\
\hline & 0.2 & $P=0.9912-0.8707$ DIVISION & 97.99 & 97.89 \\
\hline & 0.3 & $P=0.6528-0.4573$ DIVISION & 98.79 & 98.73 \\
\hline & 0.4 & $P=0.6460-4.570$ AREA_MN +0.00866 ENN_MN & 99.40 & 99.31 \\
\hline & 0.5 & $P=0.34931-1.795$ AREA_MN +0.01960 ENN_M & 95.95 & 95.55 \\
\hline \multirow[t]{6}{*}{ Farm level } & 0.05 & $P=-1.736+1.763$ DIVISION & 58.23 & 54.06 \\
\hline & 0.1 & $P=-0.778-0.000014 \mathrm{NP}+0.0405$ PAFRAC $+0.786 \mathrm{DIVISION}$ & 58.95 & 52.47 \\
\hline & 0.2 & $P=-0.9050+1.0260$ DIVISION & 96.34 & 96.17 \\
\hline & 0.3 & $P=-0.7131-0.000015 \mathrm{NP}+0.9117 \mathrm{DIVISION}$ & 98.79 & 98.73 \\
\hline & 0.4 & $P=-0.4243-0.000032$ SPLIT_1 + 0.7135 DIVISION & 97.77 & 97.54 \\
\hline & 0.5 & $P=0.39862-0.05628$ ENN_MN $+0.000865 \mathrm{Al}$ & 99.14 & 99.05 \\
\hline
\end{tabular}

increase linearly with increasing fragmentation per se. In contrast, mean patch area (Area-MN), mean Euclidean nearest-neighbor distance (ENN-MN), splitting index (SPLIT), and aggregation index (AI) decrease linearly.

In general, two metrics DIVISION and ENN-MN showed a stronger relationship with pollination than other metrics at the landscape level. The DIVISION indicates the degree of aggregation of patches, and the high numbers of this index indicate the low aggregation of the patches. The behavior of this index is the opposite of the aggregation index (AI). The negative correlation between the DIVISION index and pollination at the landscape level showed that landscapes with a high degree of fragmentation provided more pollination. The Euclidean nearest-neighbor distance (ENN-MN) shows the degree of connectivity of all patches and approaches 0 as the distance to the nearest neighbor decreases. Considering the positive relationship between this index and pollination, it can be concluded that habitat connectivity increases pollination at the landscape level (Table 2).

At the farm level, the relationship between fragmentation per se and the DIVISION was different from the landscape level. The DIVISION was positively correlated to pollination, indicating that increasing fragmentation of forest patches increased pollination at the farm level. The number of patches (NP) also confirmed the previous results. The negative relationship between this metric and pollination implied that in the landscapes where the habitat amount was constant, reducing the number of patches led to a decrease in pollination at the farm level. This effect was opposite at the landscape level though. The shape complexity of the patches was measured by the PAFRAC. This metric showed that increasing shape complexity increased pollination at the farm level (Table 2). In general, the statistical results showed that increasing aggregation, complexity, and the number of patches increased the pollination rate at the class level. However, at the landscape level, the result was different. Our results also showed that the statistical relationship between pollination and landscape metrics in low habitat amounts (less than 0.1) was not remarkable compared to other proportions at the class level.

\section{The effect of habitat loss on pollination at the landscape and farm levels}

Figure 5 shows the pollination changes caused by habitat loss in different simulated landscapes (random and fractal) at the landscape level. Pollination trend diagrams are shown for a random pattern (highest degree of fragmentation), H1 pattern (high degree of fragmentation), and H9 pattern (lowest degree of fragmentation) with slight differences of pollination levels from each other. At first sight, it can be viewed that there is a little difference between estimated pollination in fractal and random patterns. Among the datasets used in this section, the random pattern had a more fragmented pattern than the fractals, and as a result, as shown in Fig. 5 with the black line, the pollination rate was lower in random patterns than fractals. It can be concluded that fragmented patterns provided less pollination at the landscape level than aggregated patterns. It is important to note that the effect of the datasets used in modeling the effects of habitat loss on pollination was not much remarkable at the landscape level (Fig. 5). The most notable result was that pollination showed a negative linear relationship with the habitat loss trend, and the maximum level of pollination was obtained at the maximum amount of nesting habitat in all patterns.

Figure 6 shows the pollination changes according to the habitat loss trend at the farm level. In comparison with the landscape level, there is a non-linear relationship between habitat loss and pollination in the fractal 


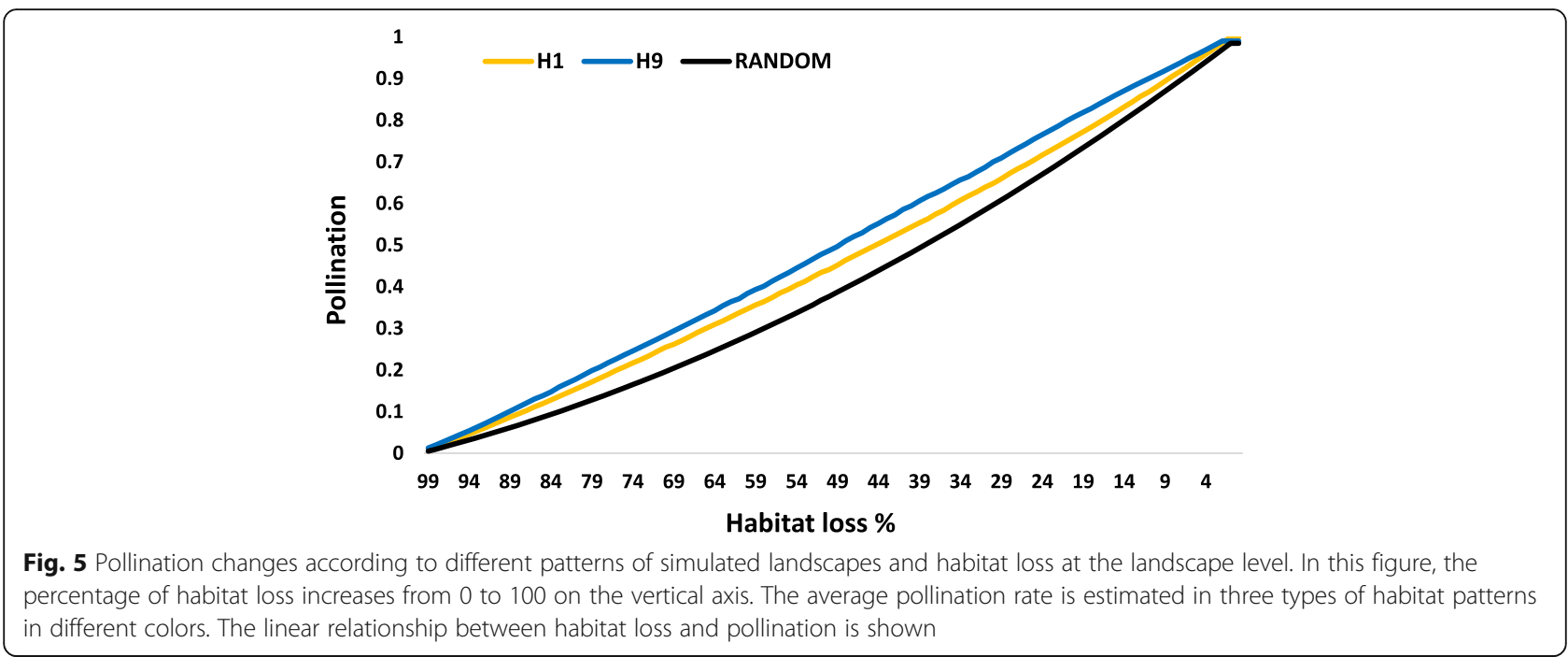

patterns. As expected, similar to the previous results, fragmented patterns increased pollination at the farm level as the random pattern showed a higher pollination rate. This result was also resembled in fractal patterns, as the $\mathrm{H} 9$ pattern that had the maximum aggregation of forest patches reduced pollination considerably. At the low levels of habitat loss, pollination decreased sharply from 0.9 to 0.1 in the $\mathrm{H} 9$ pattern at the farm level (Fig. 6). In general, the most significant effect of habitat loss on pollination was seen at the farm level that reduced the pollination rate exponentially in fractal patterns. Another notable result was that the maximum level of pollination was obtained in maximum habitat amounts in both fragmented and aggregated patterns.
Table 3 presents the results of the statistical relationship between landscape metrics and pollination according to habitat loss at the landscape and farm levels. In this table, random and fractal landscapes are presented at the mentioned levels separately. According to Table 3, the number of patches (NP) showed a significant negative relationship with pollination at both landscape and farm levels, meaning that reducing the number of patches increased pollination. The inverse relationship between the DIVISION and pollination also showed that fragmented patterns reduced pollination at both landscape and farm levels. The negative correlation of ED and PAFRAC with pollination indicated that less complex patches could

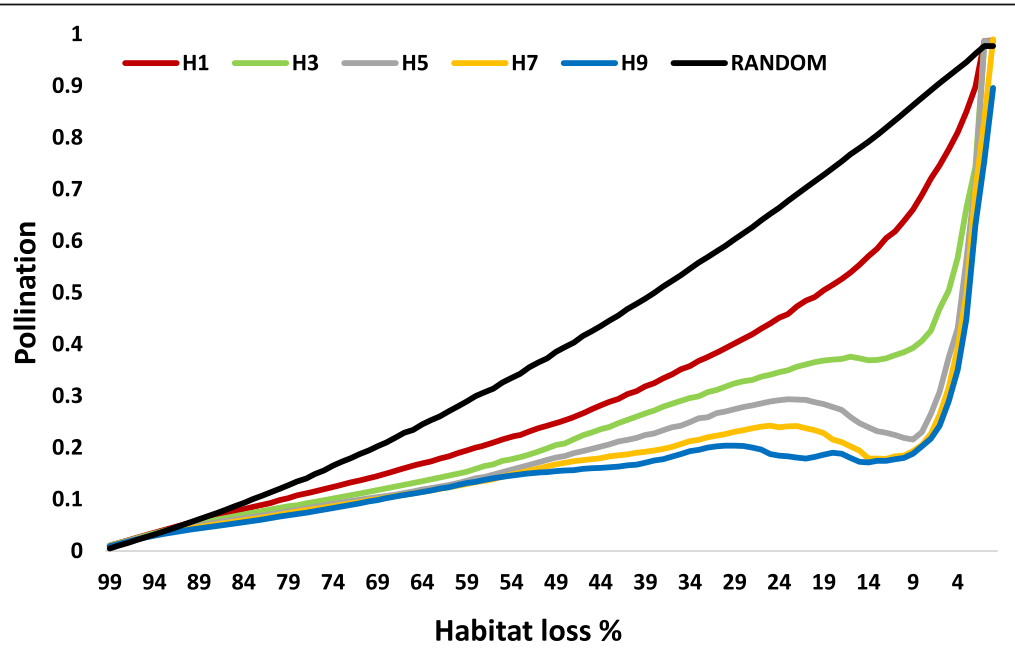

Fig. 6 Pollination changes according to different patterns of simulated landscapes and habitat loss at the farm level. In this figure, the percentage of habitat loss increases from 0 to 100 on the vertical axis. The average pollination rate is estimated in three types of habitat patterns in different colors. The non-linear relationship between habitat loss and pollination is shown for the $\mathrm{H}$ patterns 
Table 3 The statistical relationship between landscape metrics and pollination at landscape and farm levels. $P$ is the abbreviation of pollination that is the dependent variable in the regression models

\begin{tabular}{|c|c|c|c|c|}
\hline Scale & Pattern & Equation & R-Sq (\%) & R-Sq (adj) (\%) \\
\hline \multirow[t]{10}{*}{ Landscape level } & $\mathrm{H} 1$ & $P=3.2732-0.000002$ ED -1.4605 PAFRAC -21.66 ENN_MN & 98.68 & 98.63 \\
\hline & $\mathrm{H} 2$ & $P=4.626-0.005417 \mathrm{NP}-2.629$ PAFRAC -17.33 ENN_MN & 97.69 & 97.57 \\
\hline & $\mathrm{H} 3$ & $P=1.765-0.009920 \mathrm{NP}-36.28$ ENN_MN & 74.65 & 73.83 \\
\hline & $\mathrm{H} 4$ & $P=0.0386-0.001345 \mathrm{NP}-0.8450 \mathrm{DIVISION}+0.000029 \mathrm{SPLIT}$ & 99.78 & 99.77 \\
\hline & $\mathrm{H} 5$ & $P=-0.2189-0.001667 \mathrm{NP}-0.8414 \mathrm{DIVISION}+0.012248 \mathrm{Al}$ & 99.72 & 99.70 \\
\hline & $\mathrm{H} 6$ & $P=-0.3273+0.001849 \mathrm{NP}-0.000001 \mathrm{ED}+0.003757 \mathrm{Al}$ & 99.77 & 99.76 \\
\hline & $\mathrm{H} 7$ & $P=-0.473-0.1851$ PAFRAC -0.1863 ENN_MN -0.8219 DIVISION & 99.70 & 99.68 \\
\hline & $\mathrm{H} 8$ & $P=-0.971+0.000004 \mathrm{ED}-0.1412 \mathrm{ENN} \_\mathrm{MN}-0.8896 \mathrm{DIVISION}$ & 99.62 & 99.60 \\
\hline & $\mathrm{H} 9$ & $P=-1.599-0.8933 \mathrm{DIVISION}+0.000031 \mathrm{SPLIT}+0.02623 \mathrm{Al}$ & 99.65 & 99.64 \\
\hline & Random & $P=1.0115-1.626$ ENN_MN -0.9186 DIVISION & 98.91 & 98.87 \\
\hline \multirow[t]{10}{*}{ Farm level } & $\mathrm{H} 1$ & $P=3.2049-0.002157 \mathrm{NP}-1.5872$ PAFRAC -15.97 ENN_MN & 98.23 & 98.16 \\
\hline & $\mathrm{H} 2$ & $P=2.039-0.001266 \mathrm{NP}-1.019$ PAFRAC -0.5452 DIVISION & 96.77 & 96.67 \\
\hline & $\mathrm{H} 3$ & $P=0.2652-3.61$ ENN_MN -0.3554 DIVISION + $0.003723 \mathrm{Al}$ & 95.31 & 95.16 \\
\hline & $\mathrm{H} 4$ & $P=0.246+0.358$ PAFRAC -5.32 ENN_MN - 0.4899 DIVISION & 76.17 & 75.43 \\
\hline & $\mathrm{H} 5$ & $P=0.4670-0.4100$ DIVISION & 64.10 & 63.73 \\
\hline & $\mathrm{H} 6$ & $P=0.4343-0.3803$ DIVISION & 58.35 & 57.92 \\
\hline & $\mathrm{H} 7$ & $P=0.2983+0.000002 \mathrm{ED}-0.3087 \mathrm{DIVISION}$ & 73.61 & 73.06 \\
\hline & $\mathrm{H} 8$ & $P=0.2839+0.000002 \mathrm{ED}-0.2979 \mathrm{DIVISION}$ & 72.14 & 71.55 \\
\hline & $\mathrm{H} 9$ & $P=0.2724+0.000002 \mathrm{ED}-0.2850 \mathrm{DIVISION}$ & 73.10 & 72.54 \\
\hline & Random & $P=-0.0863+0.0524$ PAFRAC $+0.009868 \mathrm{Al}$ & 99.99 & 99.99 \\
\hline
\end{tabular}

provide more pollination. In general, the results of Table 3 showed that landscapes with a high degree of habitat aggregation raise pollination rate at both landscape and farm levels.

\section{Discussion}

\section{The effects of fragmentation per se on pollination}

Our results showed that fragmentation per se had both positive and negative effects on pollination according to the level of analysis (i.e., landscape and farm levels). In general, according to the Lonsdorf model, fragmentation per se declined the provision of pollination at the landscape level and, surprisingly, increased this service at the farm level. Various studies have shown that fragmentation can have both positive and negative effects on pollination (Fahrig 2017). For example, in some cases, agricultural landscapes with a high degree of habitat fragmentation raise pollination (Brosi et al. 2008). Farwig et al. (2009) reported a decrease in pollination success in fragmented patterns of forest patches. Aguilar et al. (2006) also reviewed 54 studies examining the effects of fragmentation on plant reproduction. They stated that fragmentation negatively affected plant reproduction mainly due to fragmentation effects on pollinators. In contrast, landscapes with high amounts of habitat and a low degree of fragmentation have shown higher pollinator visitation (Schüepp et al. 2014). Maurer et al. (2020) found that fragmentation negatively affected bumblebee colony size in landscapes with low habitat amounts. However, when the habitat amount was high, fragmentation was useful. Foraging activity also reached its maximum in the landscapes that had small degrees of fragmentation. The results of this study indicated that the effects of fragmentation per se were strongly dependent on the habitat amount and suggested that habitat fragmentation was not inherently adverse or useful (Maurer et al. 2020).

As mentioned above, some practical studies claimed that fragmentation effects on pollination changed concerning the amount of habitat in the landscape. Especially, recent studies have shown that fragmentation per se is useful in the landscapes with a high habitat amount and adverse in the cases that habitat amount is low (Maurer et al. 2020). However, the present study revealed another remarkable aspect of the fragmentation per se effects on pollination. Our results showed that the effects of fragmentation per se on pollination were not dependent on habitat amount and in all habitat proportions; fragmentation increased pollination at the farm level and declined it at the landscape level. Therefore, the present study considers the level of analysis as another affecting factor on pollination changes caused by 
fragmentation. Although fragmentation was useful at the farm level, it should be noted that nesting habitats that provide essential non-food resources to the pollinators, might themselves be unsuitable for wild bees by overfragmentation. Besides, highly fragmented landscapes intensify the effects of habitat loss on pollination and may eradicate any initial benefit of native pollinators (Eigenbrod 2016).

Figure 7 shows the examples of how pollination was estimated in landscapes with different degrees of fragmentation per se. This figure reveals more information about the Lonsdorf model. In the first column (a), a set of agricultural landscapes are shown, and in the second column (b), according to the Lonsdorf model, the fitness of the nesting patches was estimated according to the floral resources around them. In the last column (c), the probability of pollinators' abundance was obtained concerning the fitness of the nesting patches in the whole landscape. The results of this figure help us to understand why the Lonsdorf model offers different results at the landscape and farm levels.

In the second column (b), as it can be seen, the central cells of the patches have the highest values, and the marginal cells have lower values. The first landscape, which has a low degree of fragmentation per se, is shown with a large patch that its central cells have high values (close to 1 ). The central cells of this patch are more affected by adjacent nesting cells that have higher values than
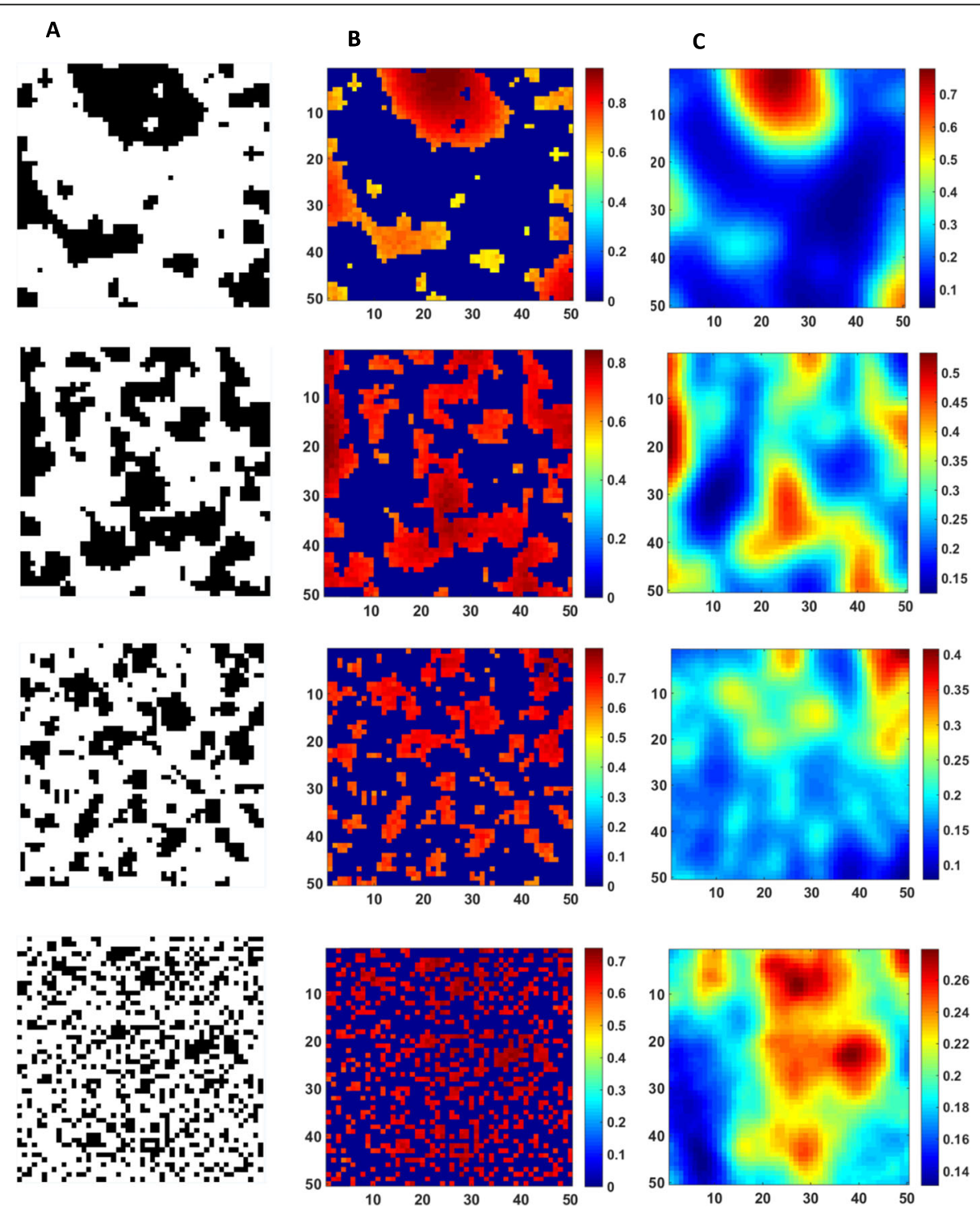

Fig. 7 Examples of estimated pollination based on the Lonsdorf model in different fragmentation patterns. The first column (a) shows the original landscapes, which are presented in different degrees of fragmentation. The second column (b) shows the fitness of the patches according to the floral resources around them, and the third column (c) shows the final maps of the pollination in the whole landscape 
adjacent foraging cells. Therefore, this patch shows more nesting fitness in its central cells. In fragmented patterns, patches are small and more impressed by adjacent foraging cells that usually have low fitness for nesting. Thus, the central cells of the patches receive low values. In aggregated patterns, patches are big and close to each other, and then, their cells are more impressed by adjacent nesting cells that this factor increases the average patch value. Therefore, bigger patches contain higher values of nesting fitness and give higher values to the surrounding environment than small ones. According to the above, at the landscape level, a high average pollination rate was seen in the landscapes with a low degree of fragmentation per se. At the farm level, we removed all the values related to the nesting patches from the calculations, and only the average pollination at the farm level was included in the calculations. Hence, in this case, fragmented patterns covered the entire landscape and affected more cells than aggregated patterns. In aggregated patterns, these patches were moved to one side of the landscape (column b, the first landscape), and as a result, there were many calls from the farms that were far away from these patches and practically received no value from these patches.

\section{The effects of habitat loss on pollination}

The present study in this section showed contradictory results with previous studies as well. At both landscape and farm levels, with decreasing the amount of nesting habitat, pollination decreased. Although this relationship was linear at the landscape level, pollination decreased exponentially at the farm level. Similar to the results of the fragmentation section, fragmentation increased the pollination at the landscape level and decreased it at the farm level (Fig. 6). Inconsistent with previous studies which have shown the maximum level of pollination at the intermediate ranges of habitat amount, i.e., about $50 \%$ of landscape (Mitchell et al. 2015a), in the present study, the maximum level of pollination was seen at the highest amounts of nesting habitat, in other words, when there was no habitat loss and the landscapes were completely covered by forest habitat. The reason given by other studies for the position of the maximum service at the intermediate ranges of habitat loss is that the provision of services such as pollination occurs only when natural and semi-natural habitats have some juxtaposition, and this juxtaposition occurs when we have some loss and fragmentation in the natural habitat (Eigenbrod 2016).

One of the assumptions of the Lonsdorf model was that it did not consider nesting habitats solely for nesting and assumed that there might be floral resources in these nesting habitats, and bees pollinate in these areas. For this reason, in the InVEST software (Sharp et al.
2014), for estimating pollination based on the Lonsdorf model, one of the required data from the user is to determine the level of suitability of nesting and foraging habitats for each land cover, which considers multiple benefits of these habitats. So here again, we are faced with the ambiguity of the Lonsdorf model, which is, why do we get the highest level of pollination when farms make up less than $1 \%$ of the entire landscape? To answer this question, we need to refer to Fig. 7. In the last column (c), it can be seen that more values of pollination are estimated in nesting habitats, implying that the high pollination rates occur in landscapes with a high percentage of nesting habitat. As a result, it is easy to conclude that increasing the amount of nesting habitat raises pollination, even if there are no farms in the landscape. Therefore, in studies claiming that pollination reaches its maximum at the intermediate ranges of habitat amount, one of their assumptions is that the nesting habitat is considered solely for nesting, and pollination in these areas is not possible.

It should be noted that Figs. 5 and 6 showed that landscapes with a high degree of fragmentation provided less pollination at the landscape level and more pollination at the farm level. In contrast, as Table 3 showed, fragmented patterns presented less pollination at both landscape and farm levels. Therefore, at first sight, it can be concluded that there is a paradox between the results presented in Table 3 and previous results. It should be emphasized that in evaluating the effects of habitat loss on pollination, the amount of habitat was not constant. Therefore, the effect of fragmented or aggregated patterns on pollination could not be estimated separately, and the habitat amount decreases constantly at each stage in the habitat loss trend.

\section{Conclusion}

The present study was one of the few studies that examined the effects of fragmentation on pollination independently of habitat loss. We found two significant and new results: (1) Effects of habitat loss and fragmentation per se on pollination at the landscape and farm levels were completely different, and (2) effects of fragmentation per se on pollination were not dependent on habitat amount. The prior can mislead landscape planners, as they cannot adopt suitable strategies to increase pollination in a landscape based on the Lonsdorf model. If they intend to increase pollination in the whole region or at the landscape level by creating new forest patches, the pattern of these patches should be aggregated. In this situation, they will face a decrease in pollination at the farm level. Therefore, it seems that the Lonsdorf model does not provide the same result for landscape and farm levels and produces confusing results in this field. In general, this model is one of the most common 
and widely used models for estimating pollination in a landscape, which can be used for different types of pollinating bees in different seasons. Our study emphasized significant alarms about the Lonsdorf model that other studies that have criticized this model (Olsson et al. 2015) have not addressed the problems.

The original native landscapes are prone to vary greatly across their ranges due to numerous human drivers (i.e., railway, road, industries, and built-up area). Besides, climatic parameters like, temperature, also affect the presence of pollinators in a landscape. Therefore, the pollinator's population and diversity are constantly changing in the landscapes. However, the present study ignored the mentioned factors and acknowledged that the results of the model used in the research might include significant uncertainty due to the limitations of the study and the difficulties with modeling a complex process like pollination. Therefore, we suggest future studies to use better models based on actual data to consider more variables affecting pollinator presence in different ecosystems.

Among the landscape metrics used in our study, several metrics showed a high correlation with pollination that can be considered as a proxy for pollination in the future. These indicators were the DIVISION, the number of patches (NP), and the mean Euclidean nearestneighbor distance (ENN-MN).

\section{Abbreviations \\ NP: Number of patches; DIVISION: Landscape division index; ENN-MN: Mean Euclidean nearest-neighbor distance; Area_MN: Mean patch area; ED: Edge density; PAFRAC: Perimeter-area fractal dimension; LSI: Landscape shape index; SPLIT: Splitting index; Al: Aggregation index}

\section{Acknowledgements}

The authors are thankful to Dr. Maghsoud Arshadi for helping in programing part of the study.

\section{Code availability}

Code available on request from the authors only based on logical requests.

\section{Authors' contributions}

ER has written the paper and has done the modeling part of the analysis. SB has reviewed the paper, helped to write, and interpreted the results. PD has reviewed the paper, edited grammar, and helped to respond to the paper's questions. The authors read and approved the final manuscript.

\section{Funding}

There are no financial conflicts of interest to disclose.

\section{Availability of data and materials}

Data are available on request from the authors only based on logical requests.

\section{Declarations}

Ethics approval and consent to participate

Not applicable

\section{Consent for publication}

Not applicable

\section{Competing interests}

The authors declare that they have no competing interest.

\section{Author details}

${ }^{1}$ Environmental Research Institute, Shahid Beheshti University, Tehran, Iran. ${ }^{2}$ Department of Geography and the Environment, University of North Texas, Denton, Texas, USA.

Received: 22 November 2020 Accepted: 25 February 2021

Published online: 22 March 2021

\section{References}

Aguilar R, Ashworth L, Galetto L, Aizen MA (2006) Plant reproductive susceptibility to habitat fragmentation: review and synthesis through a metaanalysis. Ecology Letters 9(8):968-980

Aizen MA, Garibaldi LA, Cunningham SA, Klein AM (2009) How much does agriculture depend on pollinators? Lessons from long-term trends in crop production. Annals of Botany 103(9):1579-1588

Bailey S, Requier F, Nusillard B, Roberts SP, Potts SG, Bouget C (2014) Distance from forest edge affects bee pollinators in oilseed rape fields. Ecology and Evolution 4(4):370-380

Brosi BJ, Armsworth PR. Daily GC (2008) Optimal design of agricultural landscapes for pollination services. Conservation Letters 1(1):27-36

Cambui ECB, de Vasconcelos RN, Boscolo D, da Rocha PLB, Miranda JGV (2015) GradientLand Software: a landscape change gradient generator. Ecological Informatics 25:57-62

Chong IG, Jun CH (2005) Performance of some variable selection methods when multicollinearity is present. Chemometrics and Intelligent Laboratory Systems 78(1-2):103-112

Dauber J, Biesmeijer JC, Gabriel D, Kunin WE, Lambor E, Meyer B, Nielsen A, Potts SG, Roberts SP, Sober V (2010) Effects of patch size and density on flower visitation and seed set of wild plants: a pan-European approach. Journal of Ecology 98(1):188-196

Eigenbrod F (2016) Redefining landscape structure for ecosystem services. Current Landscape Ecology Reports 1(2):80-86

Ekroos J, Rundlöf M, Smith HG (2013) Trait-dependent responses of flowervisiting insects to distance to semi-natural grasslands and landscape heterogeneity. Landscape Ecology 28(7):1283-1292

Fahrig $L$ (1998) When does fragmentation of breeding habitat affect population survival? Ecological Modelling 105(2-3):273-292

Fahrig L (2017) Ecological responses to habitat fragmentation per se. Annual Review of Ecology, Evolution, and Systematics 48:1-23

Fahrig L, Baudry J, Brotons L, Burel FG, Crist TO, Fuller RJ, Sirami C, Siriwardena GM, Martin JL (2011) Functional landscape heterogeneity and animal biodiversity in agricultural landscapes. Ecology Letters 14(2):101-112

Farwig N, Bailey D, Bochud E, Herrmann JD, Kindler E, Reusser N, Schüepp C, Schmidt-Entling MH (2009) Isolation from forest reduces pollination, seed predation and insect scavenging in Swiss farmland. Landscape Ecology 24(7): 919-927

Feder J (2013) Fractals. Springer Science \& Business Media

Fletcher RJ, Didham RK, Banks-Leite C, Barlow J, Ewers RM, Rosindell J, Holt RD, Gonzalez A, Pardini R, Damschen El (2018) Is habitat fragmentation good for biodiversity? Biological Conservation 226:9-15

Gardner RH, Turner MG, O'Neill RV, Lavorel S (1991) Simulation of the scaledependent effects of landscape boundaries on species persistence and dispersal ecotones. Springer, pp. 76-89

Garibaldi LA, Steffan-Dewenter I, Winfree R, Aizen MA, Bommarco R, Cunningham SA, Kremen C, Carvalheiro LG, Harder LD, Afik O (2013) Wild pollinators enhance fruit set of crops regardless of honey bee abundance. Science 339(6127):1608-1611

Gathmann A, Greiler HJ, Tscharntke T (1994) Trap-nesting bees and wasps colonizing set-aside fields: succession and body size, management by cutting and sowing. Oecologia 98(1):8-14

Haddad NM, Brudvig LA, Clobert J, Davies KF, Gonzalez A, Holt RD, Lovejoy TE, Sexton JO, Austin MP, Collins CD (2015) Habitat fragmentation and its lasting impact on Earth's ecosystems. Science Advances 1(2):e1500052

Häussler J, Sahlin U, Baey C, Smith HG, Clough Y (2017) Pollinator population size and pollination ecosystem service responses to enhancing floral and nesting resources. Ecology and Evolution 7(6):1898-1908 
Hegland SJ, Boeke L (2006) Relationships between the density and diversity of floral resources and flower visitor activity in a temperate grassland community. Ecological Entomology 31(5):532-538

Kennedy CM, Lonsdorf E, Neel MC, Williams NM, Ricketts TH, Winfree R, Bommarc R, Brittain C, Burley AL, Cariveau D (2013) A global quantitative synthesis of local and landscape effects on wild bee pollinators in agroecosystems. Ecology Letters 16(5):584-599

Kevan PG, Clark EA, Thomas VG (1990) Insect pollinators and sustainable agriculture. American Journal of Alternative Agriculture 5:13-22

Klein AM, Vaissiere BE, Cane JH, Steffan-Dewenter I, Cunningham SA, Kremen C, Tscharntke T (2007) Importance of pollinators in changing landscapes for world crops. Proceedings of the Royal Society B: Biological Sciences 274(1608):303-313

Kline O, Joshi NK (2020) Mitigating the effects of habitat loss on solitary bees in agricultural ecosystems. Agriculture 10(4):115

Leitão AB, Miller J, Ahern J, McGarigal K (2012) Measuring landscapes: a planner's handbook. Island Press

Lonsdorf E, Kremen C, Ricketts T, Winfree R, Williams N, Greenleaf S (2009) Modelling pollination services across agricultural landscapes. Annals of Botany 103(9):1589-1600

Maurer C, Bosco L, Klaus E, Cushman SA, Arlettaz R, Jacot A (2020) Habitat amount mediates the effect of fragmentation on a pollinator's reproductive performance, but not on its foraging behaviour. Oecologia 193:523-534

McGarigal K, Cushman SA, Neel MC, Ene E (2002) FRAGSTATS: spatial pattern analysis program for categorical maps. Available at: http://www.umass.edu/la ndeco/research/fragstats/fragstats.html

Mitchell MG, Bennett EM, Gonzalez A (2014) Forest fragments modulate the provision of multiple ecosystem services. Journal of Applied Ecology 51(4): 909-918

Mitchell MG, Bennett EM, Gonzalez A (2015a) Strong and nonlinear effects of fragmentation on ecosystem service provision at multiple scales. Environmental Research Letters 10(9):094014

Mitchell MG, Suarez-Castro AF, Martinez-Harms M, Maron M, McAlpine C, Gaston KJ, Johansen K, Rhodes JR (2015b) Reframing landscape fragmentation's effects on ecosystem services. Trends in Ecology \& Evolution 30(4):190-198

Olsson O, Bolin A, Smith HG, Lonsdorf EV (2015) Modeling pollinating bee visitation rates in heterogeneous landscapes from foraging theory. Ecological Modelling 316:133-143

Potts SG, Biesmeijer JC, Kremen C, Neumann P, Schweiger O, Kunin WE (2010) Global pollinator declines: trends, impacts and drivers. Trends in Ecology \& Evolution 25(6):345-353

Potts SG, Imperatriz-Fonseca V, Ngo H, Biesmeijer JC, Breeze T, Dicks L, Garibaldi, L, Settele J, Vanbergen AJ, Aizen MA (2016) Summary for policymakers of the assessment report of the Intergovernmental Science-Policy Platform on Biodiversity and Ecosystem Services (IPBES) on pollinators. Pollination and Food Production

Ricketts TH, Regetz J, Steffan-Dewenter I, Cunningham SA, Kremen C, Bogdanski A, Gemmill-Herren B, Greenleaf SS, Klein AM, Mayfield MM (2008) Landscape effects on crop pollination services: are there general patterns? Ecology Letters 11(5):499-515

Ryan BF, Joiner BL, Cryer JD (2012) MINITAB handbook: update for release. Learning, Cengage

Rybicki J, Hanski I (2013) Species-area relationships and extinctions caused by habitat loss and fragmentation. Ecology Letters 16:27-38

Schüepp C, Herzog F, Entling MH (2014) Disentangling multiple drivers of pollination in a landscape-scale experiment. Proceedings of the Royal Society B: Biological Sciences 281(1774):20132667

Sciaini M, Fritsch M, Scherer C, Simpkins CE (2018) NLMR and landscapetools: an integrated environment for simulating and modifying neutral landscape models in R. Methods in Ecology and Evolution 9(11):2240-2248

Sharp R, Tallis H, Ricketts T, Guerr A, Wood SA, Chaplin-Kramer R, Nelson E, Ennaanay D, Wolny S, Olwero N (2014) InVEST user's guide. The Natural Capital Project, Stanford

Steffan-Dewenter I, Schiele S (2008) Do resources or natural enemies drive bee population dynamics in fragmented habitats. Ecology 89(5):1375-1387

Syrbe RU, Walz U (2012) Spatial indicators for the assessment of ecosystem services: providing, benefiting and connecting areas and landscape metrics. Ecological Indicators 21:80-88

Tscharntke T, Sekercioglu CH, Dietsch TV, Sodhi NS, Hoehn P, Tylianakis JM (2008) Landscape constraints on functional diversity of birds and insects in tropical agroecosystems. Ecology 89(4):944-951
Viana BF, Boscolo D, Mariano Neto E, Lopes LE, Lopes AV, Ferreira PA, Pigozzo CM, Primo LM (2012) How well do we understand landscape effects on pollinators and pollination services? Journal of Pollination Ecology 7(5):31-41

Winfree R, Aguilar R, Vázquez DP, LeBuhn G, Aizen MA (2009) A meta-analysis of bees' responses to anthropogenic disturbance. Ecology 90(8):2068-2076

Winfree R, Bartomeus I, Cariveau DP (2011) Native pollinators in anthropogenic habitats. Annual Review of Ecology, Evolution, and Systematics 42:1-22

\section{Publisher's Note}

Springer Nature remains neutral with regard to jurisdictional claims in published maps and institutional affiliations.

\section{Submit your manuscript to a SpringerOpen ${ }^{\circ}$ journal and benefit from:}

- Convenient online submission

- Rigorous peer review

- Open access: articles freely available online

- High visibility within the field

- Retaining the copyright to your article

Submit your next manuscript at $\boldsymbol{\nabla}$ springeropen.com 